\title{
Using Evolutionary Algorithms to Achieve Sustainable Solutions through Household Appliances
}

\author{
Ricardo Santos ${ }^{1}$, J.C.O. Matias², Antonio Abreu ${ }^{3}$ \\ 1. ISEL-Instituto Superior de Engenharia de Lisboa, Polytechnic Institute of Lisbon, 1959-007 Lisbon, \\ GOVCOPP, University of Aveiro, 3810-193 Aveiro, Portugal \\ 2. DEGEIT_Department of Economics, Management, Industrial Engineering and Tourism, GOVCOPP, \\ University of Aveiro, 3810-193 Aveiro, C-MasT - University of Beira Interior, Portugal \\ 3. Instituto Superior de Engenharia de Lisboa, Polytechnic Institute of Lisbon,1959-007 Lisbon, CTS - Uninova, \\ Caparica, Portugal \\ E-mail: rsantos@dem.isel.ipl.pt, ajfa@dem.isel.ipl.pt, jmatias@ua.pt
}

Received: 16 April 2019; Accepted: 27 May 2019; Available online: 31 August 2019

\begin{abstract}
In order to reach a sustainable planet, there is a permanent need by the consumer (decision- agent), to achieve sustainable solutions, with its decisions. Given the importance of the buildings, as a sector to achieve such solutions, as well as the diversity of household appliances existent on the market, with all its different issues, there are several tradeoffs to consider (e.g. energy and water consumption vs initial investment), which difficult the consumer's choices from the market. The problem increases, since nowadays, the consumer tries to get a solution from the market, with a good compromise between the Economic, Social and Environmental dimensions, and according to its specific needs, which can be different from other consumers. By considering a multicriteria approach, combined with an optimization technique, based on Evolutionary Algorithms (EA), it's provided a set of sustainable solutions from the market to the consumer that respects the compromise referred before. In this work, it is presented an approach to support a decision-agent (DA) (consumer), by performing a set of sustainable choices based on household appliances from the market and suitable to its needs. Based on the obtained solutions, several savings are achieved (electrical and water consumption, $\mathrm{CO} 2$ emissions), by considering the consumer's relative importance, regarding its Economics, Environmental and Social concerns.
\end{abstract}

Keywords: Sustainable development; Energy efficiency; Electrical appliances; Life Cycle Cost Analysis (LCCA); Multi-Attribute Value Theory (MAVT); Multi objective Optimization; NSGAII.

\section{Introduction}

It is well-known, that energy plays an important key role into our society, where energetic necessities, are highly associated with issues such population's growth, economic development and technology progress [1].

Although the recent advances in technology, energy demand has risen on last years, especially regarding the last decade, threatening therefore, the last commitments made on behalf of the reduction of greenhouse gas emissions (GEE) in the atmosphere, given the high dependency of the electrical energy production, through fossil fuels [2].

According to [3-6], the reduction of energy consumption is crucial to achieve sustainability, with buildings accounting for 39 percent (approx.) of consumed energy. Based on the research in [7], and from that percentage, the residential sector represents about $15 \%$ of the final world's electric energy consumed, which represents an important sector to improve energy efficiency, through sustainable solutions/measures. According to [8], energy efficiency improvements regarding electrical household appliances, have recently arisen, not only in the European region, but as well, in other regions around the world, such as Asia, America and Africa.

Energy labeling, is one of those measures, which allows to provide relevant information to the consumer, regarding each electrical household appliance (e.g. noise, energy consumption, cloth capacity, etc.) [8-11].

However, and given the several options available in the market (brands and models) as well as the appliance's own features, it is difficult to analyze which solution would be better for the consumer [12-16].

To tackle the problem, we've applied multiple-attribute value theory (MAVT) to model consumer's choices. We've also combined MAVT with optimization techniques to support the consumer's decisions with sustainable solutions from the market.

Based on work from [17], Evolutionary Algorithms (EA), have been successfully applied to solve optimization problems with less time than other algorithms, given their stochastic nature and global search ability [18-25]. 
The purpose of this work, is therefore to present a methodology, based on MAVT and Non-Dominated Sorting Genetic Algorithm II (NSGAII), to provide the consumer with sustainable solutions from the market.

\section{Materials and methods}

\subsection{Problem description}

The problem presented here, takes into account a household consumer or a decision-agent (DA), who wants to buy from the market, a set of household appliances. Therefore, it was considered seven energy services in this case study; lighting, air conditioner, washing machine, dish washing machine, electric oven, dryer machine and refrigerator.

The DA has a limit budget to perform such decision (2100 € in this case), and he wants to achieve a set of sustainable solutions, not only good from the social point of view (by pre-selecting the appliances according to its needs), but a set of solutions that allows them to achieve a good compromise between its economic and environment concerns, which are expressed as a set of two relative importance factors (weights), respectively $\omega_{A}$ (0.7) and $\omega_{B}(0.3)$.

There were considered four occupants (DA included) in the building. Given his intention into acquire an air conditioner (and based on the well-known room area to be climatized), the corresponding heating and cooling needs were considered and calculated.

The consumption profile was performed, by making a set of assumptions based on the hours, which was then extrapolated to a weekly and year base, although this can be done by the DA, by defining itself, its usage profile, according to its needs.

\subsection{Data}

Additionally to the data referred to before, regarding the criteria used and consumer usage profile, data regarding the electricity consumption were considered, according to the consumer usage profile, i.e., on an hourly, daily, monthly and yearly basis, even then extrapolated for the lifecycle considered in this case study (10 years), performing a LCCA, regarding each appliance from each energy service, during the usage phase.

Data regarding the initial investment, as well as the criteria referred above and the remain data (brand and model) regarding each appliance, was also considered.

\subsection{Proposed approach}

The approach presented here, was developed to support a DA who wants to buy a set of household appliances existed on market.

At first, a set of potential solutions $\left(x_{i j}\right)$ are pre-selected from the market, according to specific criteria, according to building occupants. The criteria are the same, although the value of the correspondent attributes can change according to the building number of occupants.

This pre-selection allows to reduce the decision space, accounting only the solutions, suitable to the consumer needs, as well as to increase NSGAII efficiency, by achieving optimal solutions with less time.

Each one of these potential solutions $\left(x_{i j}\right)$, is then formulated as an option $i$, regarding energy service $j$, to be acquired by the DA (consumer) from the market.

Given a DA consumption profile, LCCA is then preformed to achieve, for each appliance, the corresponding savings, regarding energy consumption $\left(S_{E . \text { Cons }_{i, j}}\left(x_{i j}\right)\right)$, water consumption $\left(S_{H 20 . \text { Cons }_{i, j}}\left(x_{i j}\right)\right)$ as well as the initial investment $\left(S_{i n v_{i, j}}\left(x_{i j}\right)\right)$. Both parameters, are savings, obtained from the comparison between the efficient and the correspondent "standard solution" (less efficient one).

Given the diversity of features, regarding each solution, as well as the DA's economic, social and environmental concerns, a set of attributes was defined according to the consumer preferences and regarding each energy service, for the two problem dimensions considered; A-Economics, B-Environment (Table 1).

Apart from the energy efficiency classification, regarding each energy label, belonging to each energy service, all the adopted attributes can be applied into other regions. In this case, the EU's Energy Labelling framework Regulation (2017/1369) was adopted.

The consumption profile was performed, by making a set of assumptions based on the hours, which was then extrapolated to a weekly and year base. However, the decision-agent (consumer) can also define its usage profile according to its needs, or by using the profile, considered in the case study presented here, as a default.

As referred to before, MAVT is used to support the DA, by evaluating a set of alternative solutions, according to a set of criteria/attributes established (Table 1).

On Tables 2 a) and 2 b), it's shown an example for a table, related to energy service "Lighting” and regarding the attributes and correspondent values, respectively. 
Table 1. Attributes used to define problem dimensions, regarding each energy service considered

\begin{tabular}{|c|c|c|c|c|}
\hline $\begin{array}{l}\text { Energy } \\
\text { Service } \\
\end{array}$ & A - Economics & Ref. & B - Environment & Ref. \\
\hline \multirow[t]{3}{*}{ Ilu -lighting } & Energy Efficiency Classification & Ilu.A1 & $\begin{array}{l}\mathrm{CO}_{2} \text { e Emissions (Life Cycle - } \\
\text { Usage Phase) [kg] }\end{array}$ & Ilu.B1 \\
\hline & $\begin{array}{l}\text { Energy Cons. Savings (Life Cycle - } \\
\text { Usage phase) [€] }\end{array}$ & Ilu.A2 & $\begin{array}{l}\mathrm{CO}_{2} \mathrm{e} \text { Emissions (Life Cycle - } \\
\text { Production Phase) }[\mathrm{kg}]\end{array}$ & Ilu.B2 \\
\hline & $\vdots$ & $\vdots$ & $\vdots$ & $\vdots$ \\
\hline \multirow[t]{3}{*}{$\begin{array}{l}\text { AC - Air } \\
\text { Conditioner }\end{array}$} & $\begin{array}{l}\text { Energy Efficiency Classification } \\
\text { (Heating) }\end{array}$ & AC.A2 & $\begin{array}{l}\mathrm{CO}_{2} \mathrm{e} \text { Emissions (Life Cycle - } \\
\text { Production Phase) [kg] }\end{array}$ & AC.B2 \\
\hline & $\begin{array}{l}\text { Energy Efficiency Classification } \\
\text { (Cooling) }\end{array}$ & AC.A3 & $\begin{array}{l}\mathrm{CO}_{2} \mathrm{e} \text { Emissions (Life Cycle - End } \\
\text { Use Phase) [kg] }\end{array}$ & AC.B3 \\
\hline & $\vdots$ & $\vdots$ & $\vdots$ & $\vdots$ \\
\hline \multirow{3}{*}{$\begin{array}{l}\text { MLR - } \\
\text { Washing } \\
\text { Machine }\end{array}$} & Energy Efficiency Classification & MLR.A.1 & $\begin{array}{l}\mathrm{CO}_{2} \mathrm{e} \text { Emissions (Life Cycle - } \\
\text { Usage Phase) [kg] }\end{array}$ & MLR.B.1 \\
\hline & $\vdots$ & $\vdots$ & $\vdots$ & $\vdots$ \\
\hline & $\begin{array}{l}\text { Water Cons. Savings (Life Cycle - } \\
\text { Usage phase) [€] }\end{array}$ & MLR.A.4 & $\begin{array}{l}\text { Water Consumption (Life Cycle - } \\
\text { Usage phase) [1] }\end{array}$ & MLR.B.4 \\
\hline \multirow{2}{*}{$\begin{array}{l}\text { MSR - } \\
\text { Dryer } \\
\text { Machine }\end{array}$} & $\vdots$ & $\vdots$ & $\vdots$ & $\vdots$ \\
\hline & $\begin{array}{l}\text { Investment Savings (Life Cycle - } \\
\text { Usage Phase) [€] }\end{array}$ & MSR.A.3 & $\begin{array}{l}\mathrm{CO}_{2} \mathrm{e} \text { Emissions (Life Cycle - End } \\
\text { Use Phase) [kg] }\end{array}$ & MSR.B3 \\
\hline $\begin{array}{l}\text { FRIG. - } \\
\text { Refrigerator }\end{array}$ & $\vdots$ & $\vdots$ & $\vdots$ & $\vdots$ \\
\hline FE - Oven & $\vdots$ & $\vdots$ & $\vdots$ & $\vdots$ \\
\hline \multirow{2}{*}{$\begin{array}{l}\text { MLL - } \\
\text { Dishwasher }\end{array}$} & $\vdots$ & $\vdots$ & $\vdots$ & $\vdots$ \\
\hline & $\begin{array}{l}\text { Water Cons. Savings (Life Cycle - } \\
\text { Usage phase) [€] }\end{array}$ & MLL.A.4 & $\begin{array}{l}\text { Water Consumption (Life Cycle - } \\
\text { Usage phase) [1] }\end{array}$ & MLL.C.4 \\
\hline
\end{tabular}

a) Attribute, $x_{i j}^{\left(g_{j t}\right)}$

Table 2. Example of evaluation table (lighting):

\begin{tabular}{cccccccc}
\hline lighting & $A .1 \cdot 1$ & $\ldots$ & & $A . n_{\cdot 1}$ & $B .1 \cdot 1$ & $\ldots$ & $B . n_{\cdot 1}$ \\
\hline$X_{11}$ & $x_{11}^{(A .1 .)}$ & & $\ldots$ & $x_{1 n_{1}}^{\left(A . n_{A t} .\right)}$ & $x_{11}^{(B .1)}$ & $\ldots$ & $x_{11}^{\left(B . n_{B 1}\right)}$ \\
$X_{21}$ & $x_{21}^{(A .1 .)}$ & & $\ldots$ & $x_{1 n_{1}}^{\left(A . n_{A t} .\right)}$ & $x_{21}^{(B .1)}$ & $\ldots$ & $x_{21}^{\left(B . n_{B 1}\right)}$ \\
$\ldots$ & $\ldots .$. & & $\ldots$ & $\ldots$ & $\ldots$ & $\ldots$ \\
$X_{101}$ & $x_{101}^{(A .1 .)}$ & & $\ldots$ & $x_{1 n_{1}}^{\left(A . n_{A t} .\right)}$ & $x_{101}^{(B .1)}$ & $\ldots$ & $x_{101}^{(B . B 1)}$ \\
\hline
\end{tabular}

b) Correspondent value, $v_{i j}\left(x_{i j}^{\left(g_{j t}\right)}\right)$

\begin{tabular}{ccccccc}
\hline lighting & $A .1_{1}$ & $\ldots$ & $A \cdot n_{\cdot 1}$ & $B .1 \cdot 1$ & $\ldots$ & $B . n_{\cdot 1}$ \\
\hline$X_{11}$ & $v_{11}\left(x_{11}^{(A .1 .)}\right)$ & $\ldots$ & $v_{11}\left(x_{1 n_{1}}^{\left(A . n_{1} \cdot\right)}\right)$ & $v_{11}\left(x_{11}^{(B .1)}\right)$ & $\ldots$ & $v_{11}\left(x_{11}^{\left(B . n_{B 1}\right)}\right)$ \\
$X_{21}$ & $v_{21}\left(x_{21}^{(A .1 .)}\right)$ & $\ldots$ & $v_{21}\left(x_{2 n_{1}}^{\left(A . n_{A 1} \cdot\right)}\right)$ & $v_{21}\left(x_{21}^{(B .1)}\right)$ & $\ldots$ & $v_{21}\left(x_{21}^{\left(B . n_{B 1}\right)}\right)$ \\
$\ldots$ & $\ldots$ & $\ldots$ & $\ldots$ & $\ldots$ & $\ldots$ & $\ldots$ \\
$X_{101}$ & $v_{101}\left(x_{101}^{(A .1 .)}\right)$ & $\ldots$ & $v_{101}\left(x_{101}^{\left(A . n_{A 1} \cdot\right)}\right)$ & $v_{101}\left(x_{101}^{(B .1)}\right)$ & $\ldots$ & $v_{101}\left(x_{101}^{\left(B . n_{B 1}\right)}\right)$ \\
\hline
\end{tabular}

Based on the value attributes, previously achieved, it was used the additive model to aggregate them, referred to each option $i$, regarding energy service $j$, which was further improved, by applying optimization techniques, by using NSGAII algorithm. 
The consumer will face a problem of the type of a combinatorial (Figure1), where the number of combinations is dependent on the number of individual solutions to be considered, related to each energy service (23 million combinations in the case study considered here). This number of combinations can be reduced by assuming that the consumer cannot perform any choices $\left(\mathrm{x}_{i j}\right)$, given his limited budget.

Constraints like the air conditioner capacity and appliances noise maximal requirements will also be accounted for to suit consumer needs in order to improve its social wellbeing.

After defining the value attributes of each potential solution, and by using the additive model, the problem presented here can be formulated as follows:

$$
\begin{array}{ll}
\max V_{m}(x), & \frac{c}{m}=A, B \\
\text { s.t. } x \in X & c / V_{m}(x)=\left[V_{A}(x), V_{B}(x)\right]^{T}
\end{array}
$$

Where $x$ is the decision variable vector, defined as:

$$
x \in X: x \in\left\{x_{i j}^{\left(A_{j t}\right)}, x_{i j}^{\left(B_{j t}\right)}\right\} \wedge t, i, j \in \mathbb{N}
$$

with

$$
j=\{1, \ldots, 10\} \wedge j=\{1,2, \ldots, 7\} \wedge t=\left\{\left\{1, \ldots, n_{A_{j}}\right\} \cup\left\{1, \ldots, n_{B_{j}}\right\}\right\} \wedge n_{A_{j}}, n_{B_{j}} \in \mathbb{N}
$$

where $V_{A}(x)$ and $V_{B}(x)$, are the aggregate objective functions, regarding each dimension considered (AEconomics; B-Environment):

$$
V_{g}(x)=\sum_{j=1}^{n_{j}} \sum_{t=1}^{n_{g_{j}}} v_{j}\left(x_{j}^{\left(g_{j t}\right)}\right) w / g=\{A, B\} \wedge v_{j}\left(x_{j}^{\left(g_{j t}\right)}\right) \wedge n_{j}, n_{g_{j}}, t, j \in \mathbb{N}
$$

Therefore, the objective functions are:

$$
\begin{aligned}
& \text { EconomicWell - being: } \max V_{A}(x)=\sum_{j=1}^{n_{j}} \sum_{t=1}^{n_{A_{j}}} v_{j}\left(x_{j}^{\left(A_{j t}\right)}\right) \\
& \text { EnvironmentWell - being: } \max V_{B}(x)=\sum_{j=1}^{n_{j}} \sum_{t=1}^{n_{B_{j}}} v_{j}\left(x_{j}^{\left(B_{j t}\right)}\right)
\end{aligned}
$$

The first objective function is based through the works of [20][26].

By using the additive model from MAVT, the aggregated function results in a unique objective function, weighted by the decision-agent relative importance $\left(\omega_{g}\right)$ as follows:

$$
V\left(V_{A}(x), V_{B}(x)\right)=\omega_{A} \cdot V_{A}(x)+\omega_{B} \cdot V_{B}(x)=\sum_{j=1}^{n_{j}}\left(\omega_{A} \sum_{t=1}^{n_{A}} v_{j}\left(x_{j}^{\left(A_{j t}\right)}\right)+\omega_{B} \sum_{t=1}^{n_{B_{j}}} v_{j}\left(x_{j}^{\left(B_{j t}\right)}\right)\right)
$$

The constraints, regarding economic and environment well-being/dimensions, are:

Economic-Budget:

$$
r_{1}: \sum_{j=1}^{n_{\text {dim }}} I_{j}\left(x_{j}\right) \leq \text { available budget }\left(\eta_{\text {disp. }}\right) \Leftrightarrow \sum_{j=1}^{n_{\text {dim }}} x_{j}^{\left(A_{j t}\right)} \leq \eta_{\text {disp. }}
$$

with

$$
A_{j t}=\left\{A_{14}, A_{26}, A_{35}, A_{44}, A_{54}, A_{64}, A_{75}\right\} \wedge n_{\mathrm{dim}}, t, j \in \mathbb{N}
$$

Environment-Noise:

$$
r_{j}: \text { Noise }_{j} \leq \text { Max. Noise } \text { N }_{j} \Leftrightarrow x_{j}^{\left(B_{j t}\right)} \leq \text { Max. Noise }_{j}
$$

with: 


$$
B_{j t}=\left\{B_{24}, B_{35}, B_{44}, B_{54}, B_{64}, B_{75}\right\} \wedge n_{\mathrm{dim}}, t, j \in \mathbb{N}
$$

As referred to before, NSGAII's codification used was real so that it can only be chosen in one individual solution, regarding each type of appliance at the time.

The model will be applied, using the case study presented before, and by considering a consumer (DA), who wants to buy seven energy services.

\section{Results and discussion}

NSGAII was implemented by using Matlab code and considering the parameters from Selection method (tournament), Crossover method (single point) and Mutation (normal random).

The remaining NSGA-II parameters (initial population, crossover and mutation rate) were defined after several runs.

Other parameters such as the population size (120 individuals), the tournament size (12), the crossover rate (0.8), and the mutation rate $(0.3)$ were also tested.

It was selected a parameter value of 90, for the max number of iterations/generations and it was preformed several combinations of crossover and mutation rates of NSGA-II (Table 3) to achieve the best combination.

Table 3. Crossover combinations and mutation rates used

\begin{tabular}{lll}
\hline Experiment & Crossover Rate & Mutation Rate \\
\hline 1 & 0.8 & 0.1 \\
2 & 0.8 & 0.3 \\
3 & 0.9 & 0.1 \\
4 & 0.9 & 0.3 \\
\hline
\end{tabular}

The combinations, presented on Table 3, were performed by setting a max iteration of 90 . The correspondent results are shown on Figure 1 where it's noted that the small change on parameters, had a reduced effect in the results. Thus, NSGAII's parameters were used to show the results of the present case: population size (100), max iteration (90), tournament size (12), crossover rate $(0,8)$ and mutation rate $(0,3)$.

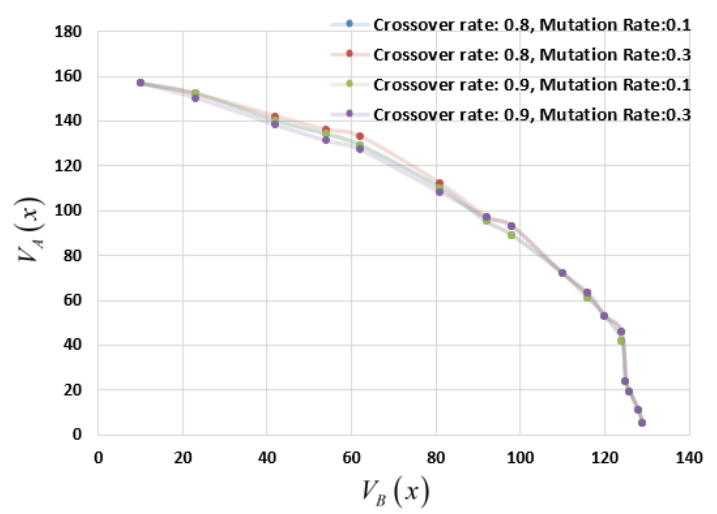

Figure 1. Pareto frontier, considering different value’s parameters of NSGAII.

The Pareto frontier (Figure 2) is therefore obtained, with each node representing a potential solution of the problem, i.e., a set of sustainable solutions (appliances) regarding each energy service required by the DA.

Based on Figure 2, it is noted that, although the economic well-being decreases, the environmental well-being increases, which highlights the obtained Pareto frontier.

Thirteen potential solutions were then selected, regarding the last generation obtained by the algorithm, as an example of a Pareto frontier.

One of these nodes are presented on Table 4, as an example of a feasible solution, considering a budget of 2100 $€$ and a life cycle (usage phase) of 10 years.

The $\mathrm{CO}_{2}$ savings are also presented, regarding the choice of this solution, compared with the less efficient (standard) one (approx. values).

According to Table 4, if the DA, choose the solutions, provided by this approach, it can be saved up to 2112,3 $€$, further contributing to a 1458,9 $\mathrm{kg}$ of $\mathrm{CO}_{2}$ and 740 liters of water, both savings/years, according to the life cycle considered. 


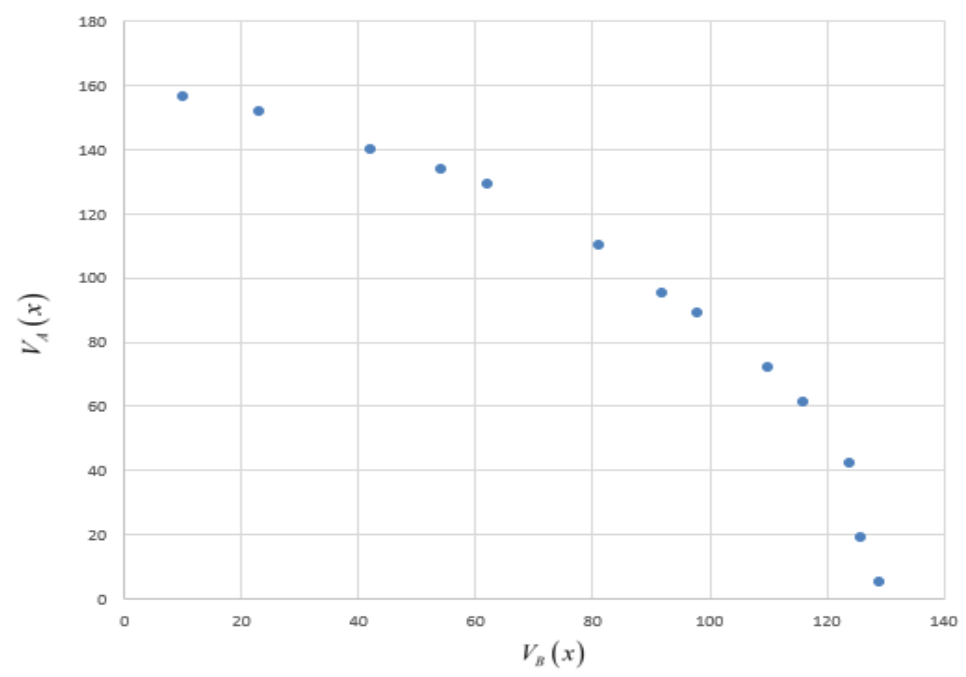

Figure 2. Pareto frontier of the last generation.

Table 4. Example of a sustainable solution obtained from this approach

\begin{tabular}{|c|c|c|c|c|c|c|c|c|}
\hline Dimension & $\begin{array}{l}\text { Stand. } \\
\text { Solution } \\
\text { Total Invest. } \\
\text { (€) }\end{array}$ & $\begin{array}{l}\text { Effic. } \\
\text { Solution } \\
\text { Total } \\
\text { Invest (€) }\end{array}$ & $\begin{array}{l}\text { Investme } \\
\text { nt } \\
\text { Savings } \\
\text { (€) }\end{array}$ & $\begin{array}{l}\text { Energy } \\
\text { Consum. } \\
\text { Savings (€) }\end{array}$ & $\begin{array}{l}\text { Water } \\
\text { Consum. } \\
\text { Savings (l) }\end{array}$ & $\begin{array}{l}\mathrm{CO}_{2} \\
\text { Savings } \\
\text { (kg) }\end{array}$ & Brand & Model \\
\hline Lighting & 15,92 & 09,53 & 5,35 & 59,40 & - & 28,90 & GE & EFL23W \\
\hline $\begin{array}{l}\text { Air } \\
\text { Conditioning }\end{array}$ & 378,00 & 299,00 & 69,10 & 1320,60 & - & 1315,70 & Bosch & PACW9HP \\
\hline Refrigerator & 250,00 & 529,00 & $-279,00$ & 708,10 & - & 8,70 & Candy & CFET 6182W \\
\hline $\begin{array}{l}\text { Dishwasher } \\
\text { Machine }\end{array}$ & 320,00 & 349,00 & $-39,00$ & 3,20 & 423,10 & 6,92 & Bosch & SMS25AI00E \\
\hline $\begin{array}{l}\text { Washing } \\
\text { Machine }\end{array}$ & 262,00 & 294,00 & $-32,00$ & 6,90 & 317,25 & 94,80 & Siemens & WI12A222ES \\
\hline Oven & 171,00 & 199,00 & $-29,00$ & 1,70 & - & 2,20 & Zanussi & ZZB21601XV \\
\hline Clothes dryer & 349,00 & 419,00 & $-70,00$ & 12,30 & - & 1,71 & Electrolux & EDP2074PDW \\
\hline Total & 1745,93 & 2099,60 & $-374,81$ & 2112,30 & 740,35 & 1458,93 & - & - \\
\hline
\end{tabular}

\section{Conclusions}

In this work, it was presented an approach to provide sustainable electrical household appliances from the market to the decision-agent (consumer), considering two problem dimensions (objectives), and regarding sustainability; environment and economic well-being.

Criteria was used to pre-select the appliances from the market, and, to modelling the consumer preferences, according to the two problem dimensions presented here.

The purpose was to maximize the consumer well-being (environment and economics) with the social wellbeing also promoted, by choosing the solutions according to the consumer needs.

The relative importance, given by the DA (consumer), was also considered, in order to weight the DA decision through both dimensions.

NSGAII, combined with MAVT, where then applied here, to get optimal solutions, by maximizing both dimensions, considering the environmental impact, as well as the economic rationality, by considering the lifecycle of each appliance, during its usage phase.

The results show, that this method performs well in this case, by providing optional (and sustainable) appliances that attends the consumer needs.

The results obtained on this work, allows to proceed in a way of getting a more completed approach, in order to maximize both dimensions of sustainability; Economical, Environmental and Social. 
The social dimension, although implicit through consumer preferences and needs, will be more explicit, by being expressed through a 3rd Dimension to be included in the model.

As referred before, the Life Cycle Cost Analysis (LCCA), only accounts the usage phase in this work, bringing up the need to include the remaining LCCA phases (Production and Final Disposal) as further developments to be considered in this work.

Based on what was referred before, and apart from Energy Efficiency Classification, the approach presented here, can be applied into other world's regions, although adjusted to each consumer's individual needs.

\section{References}

[1] Matias JCO, Devezas TC. Socio-economic development and primary energy sources substitution towards decarbonization. Low Carbon Economy. 2011;2(02):49-53.

[2] IPCC. Climate Change 2014: Mitigation of climate change summary for policymakers and technical summary. Intergovernmental Panel on Climate Change (IPCC);2015.

[3] IEA. Energy efficiency 2017- Market Reports Series. OECD/IEA;2017.

[4] https://ec.europa.eu/clima/policies/strategies/2020_en

[5] https://www.consilium.europa.eu/en/policies/climate-change/2030-climate-and-energy-framework/

[6] Gul MS, Patidar S. Understanding the energy consumption and occupancy of a multi-purpose academic building. Energy and Buildings. 2015;87:155-165.

[7] Santos CP. Rehabilitation of buildings to promote comfort and energy efficiency. In: Net-Zero Energy Buildings Conference (1st) LNEG. Lisboa;2012. (in Portuguese)

[8] EES. Energy standards and labelling programs throughout the world in 2013. Energy Efficiency Strategies and Maia Consulting for the Australian Department of Energy. Victoria;2014.

[9] ADENE. Energy label manual. Lisbon: ADENE; 2017. (in Portuguese)

[10] DGEG. Energy efficiency in buildings - E4 Program. General Direction of Energy and Geology. Lisbon; 2002. (in Portuguese)

[11] Wong L, Krüger E. Comparing energy efficiency labelling systems in the EU and Brazil: Implications, challenges, barriers and opportunities. Energy Policy. 2017;109:310-323.

[12] Fell M. Energy services: A conceptual review. Energy Research \& Social Science. 2017;27:129-140.

[13] Hoxha E, Jusselme T. On the necessity of improving the environmental impacts of furniture and appliances in net-zero energy buildings. Science of The Total Environment. 2017;596:405-416.

[14] Ting TO, Rao MV, Loo CK. A novel approach for unit commitment problem via an effective hybrid particle swarm optimization. IEEE Transactions on Power Systems. 2006;21(1):411-418.

[15] Ko M, Kim Y, Chung M, Jeon H. Multi-objective optimization design for a hybrid energy system using the genetic algorithm. Energies. 2015;8(4):2924-2949.

[16] Randall M, Rawlins T, Lewis A, Kipouros T. Performance comparison of evolutionary algorithms for airfoil design. Procedia Computer Science. 2015;51:2267-2276.

[17] Goldberg D. Genetic algorithms in search optimization and machine learning. Maryland: Addison Wesley; 1989.

[18] Chuah JW, Raghunathan A, Jha NK. ROBESim: A retrofit-oriented building energy simulator based on EnergyPlus. Energy and Buildings. 2013;66:88-103.

[19] Pombo O, Allacker K, Rivela B, Neila J. Sustainability assessment of energy saving measures: A multicriteria approach for residential buildings retrofitting-A case study of the Spanish housing stock. Energy and Buildings. 2016;116:384-394.

[20] Santos R, Abreu A, Matias JCO. Energy efficiency in buildings by using evolutionary algorithms: An approach to provide efficiency choices to the consumer, considering the rebound effect. In: IFIP International Federation for Information Processing; 2018.

[21] Asadi E, Da Silva MG, Antunes CH, Dias L. Multi-objective optimization for building retrofit strategies: A model and an application. Energy and Buildings. 2012;44:81-87.

[22] Caccavelli D, Gugerli HT. TOBUS-a European diagnosis and decision-making tool for office building upgrading. Energy and Buildings. 2002;34(2):113-119.

[23] Kaklauskas A, Zavadskas EK, Raslanas S. Multivariant design and multiple criteria analysis of building refurbishments. Energy and Buildings. 2005;37(4):361-372.

[24] Pombo O, Allacker K, Rivela B, Neila J. Sustainability assessment of energy saving measures: A multicriteria approach for residential buildings retrofitting-A case study of the Spanish housing stock. Energy and Buildings. 2016;116:384-394.

[25] Jafari A, Valentin V. An optimization framework for building energy retrofits decision-making. Building and Environment. 2017;115:118-129. 
[26] Santos RS, Matias JC, Abreu A, Reis F. Evolutionary algorithms on reducing energy consumption in buildings: An approach to provide smart and efficiency choices, considering the rebound effect. Computers \& Industrial Engineering. 2018;126:729-755.

(C) 2019 by the author(s). This work is licensed under a Creative Commons Attribution 4.0 International License (http://creativecommons.org/licenses/by/4.0/). Authors retain copyright of their work, with first publication rights granted to Tech Reviews Ltd. 